\title{
A representação de conceitos educacionais interdisciplinares no projeto criativo de um game inteligente
}

\author{
Raquel M. M. Fernandes ${ }^{1}$, Cláudia Lage Rebello da Motta², Luis Felipe A. Fernandes ${ }^{3}$
}

${ }^{1}$ Programa de Pós Graduação em Informática (PPGI) - Instituto Tércio Pacitti de Aplicações e Pequisas Computacionais - Universidade Federal do Rio de Janeiro (UFRJ) / Instituto de Ciências Exatas (ICEX) - Universidade Federal Fluminense (UFF)

${ }^{2}$ Programa de Pós Graduação em Informática (PPGI) - Instituto Tércio Pacitti de Aplicações e Pequisas Computacionais - Universidade Federal do Rio de Janeiro (UFRJ)

\author{
${ }^{3}$ Universidade Federal Rural do Rio de Janeiro (UFRRJ) \\ raquelmachado@id.uff.br, claudiam@nce.ufrj.br, \\ luisfelipeamerico@ufrrj.br
}

\begin{abstract}
Given a context in which Neuroscience and Education form a triad with technology seeking to provide more effective and ludified learning processes, this article presents results of the creative project of a game drive of narrative discourse and emphasizes the importance of the study of Metaphors and Semiotics for representation of concepts during the construction of an interface.

Resumo. Dado um contexto em que a Neurociência e a Educação formam uma tríade com a tecnologia buscando proporcionar processos de aprendizado mais efetivos e ludificados, este artigo apresenta resultados do projeto criativo de um game impulsionador do discurso narrativo e ressalta a importância do estudo das Metáforas e da Semiótica para representação de conceitos durante a construção de uma interface.
\end{abstract}

\section{Introdução}

A respeito do conceito de games inteligentes, sabe-se, segundo Marques[2015], que trata-se de um software ludificado segundo uma metodologia pedagógica de base neurocientífica metacognitiva com o objetivo de expandir um mais aprendizados. Um game inteligente, portanto, compõe uma classe de jogos diferenciados por requerer a elaboração de um modelo científico capaz de mapear dados cognitivos durante o processo de interação do jogador, possibilitando concomitantemente uma análise da assinatura cognitiva do jogador e uma mediação impulsionadora de saltos cognitivos. Este artigo tem como objetivo apresentar conceitos e atividades realizadas na etapa de projeto criativo de um game inteligente, com base na metodologia proposta por Motta et al. [2014].

O game desenvolvido considerou a necessidade e o contexto educacional de 20 crianças do sexto ano do ensino fundamental da escola Municipal Charles Anderson Weaver, localizada na região de Costa Barros, penúltima no ranking de IDH do Rio de Janeiro. A criação de um projeto interdisciplinar entre os docentes envolvidos possibilitou a inserção das Ciências Biológicas no âmbito desta pesquisa.

\section{Trabalhos relacionados}

O enfoque do game cujo projeto criativo é apresentado, é estimular o aprendizado dos gêneros textuais fomentando a leitura do mundo e a produção textual em gênero narrativo com base em um modelo computacional da criatividade estabelecido a partir da teoria de Seminério[1997].

Para tanto, foram pesquisados trabalhos sobre games inteligentes, linguística, 
VII Congresso Brasileiro de Informática na Educação (CBIE 2018)

Anais do XXIX Simpósio Brasileiro de Informática na Educação (SBIE 2018)

neurociência e tecnologias. "O jogo da trilha topológica" [Motta 2012] e "O jogo das cartas voadoras"[Pimentel 2014] demonstram a possibilidade de análise da assinatura cognitiva do jogador e a mediação virtual voltada para o salto cognitivo.

\section{Metodologia}

Inicialmente foi realizado um extenso trabalho de modelagem dimensional para seleção de domínios e grandezas.

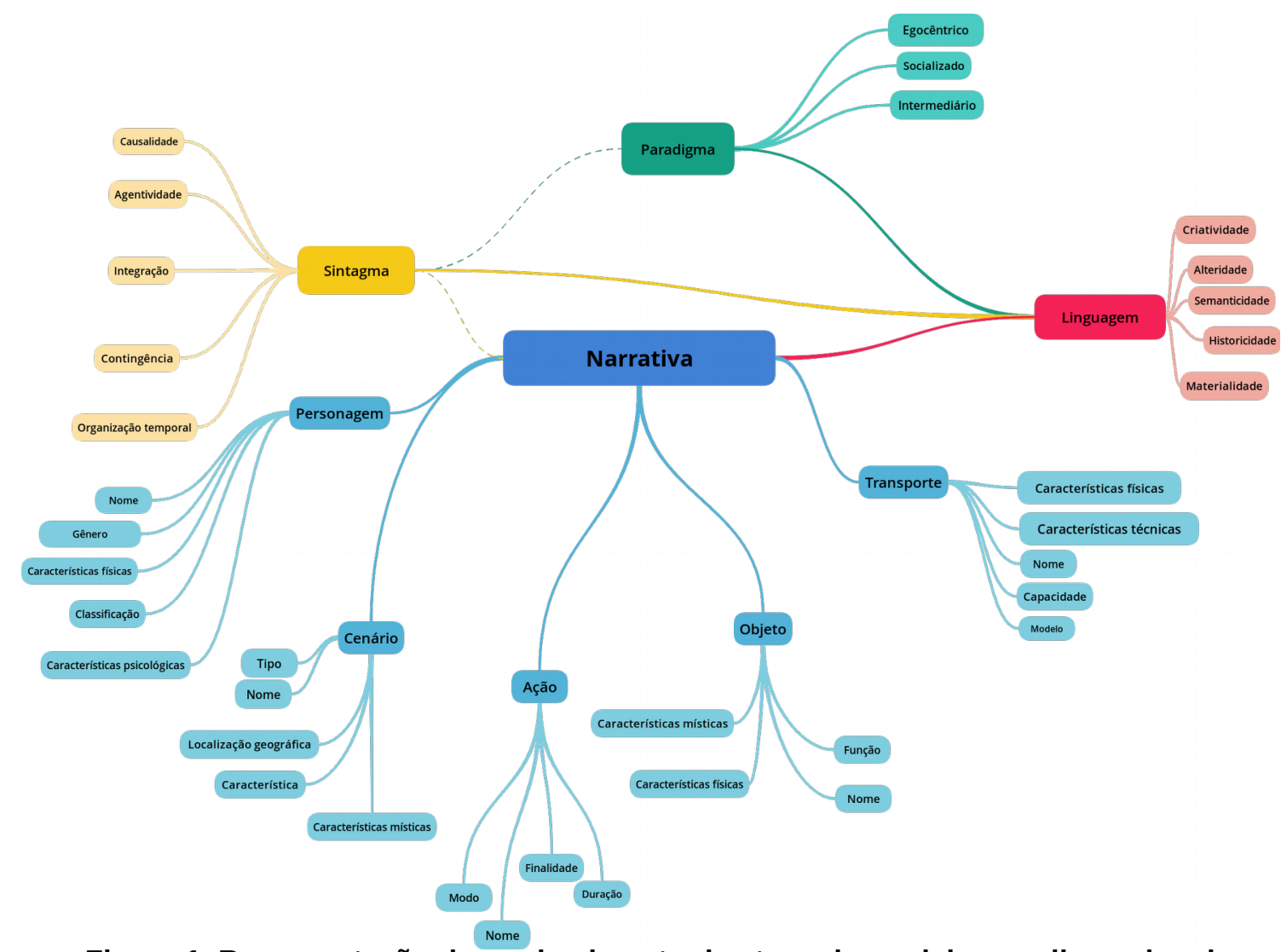

Figura 1. Representação do conhecimento da etapa de modelagem dimensional

Para o início do processo criativo, buscou-se analisar quais seriam os gêneros de jogos que poderiam adequar-se melhor às atividades digitais relacionadas ao gênero narrativo. Os resultados desta pesquisa retornaram um conhecimento a respeito do gênero Visual Novel.

Visual Novel é um gênero de jogo focado em narrativas. O jogo é composto por textos, músicas e imagens estáticas ou em animações curtas, como GIFs. O desenvolvimento da trama do jogo depende das escolhas do usuário.

Esta modalidade de jogo permite a construção de seguimentos múltiplos na história, o que torna única cada experiência de jogada. Para o game em questão, baseado em cinco dimensões narrativas oriundas do processo de modelagem dimensional, o enredo base do jogo já apresenta 3125 possibilidades de jogada.

Este número pode ser ainda maior, se o somarmos às possibilidades de escolha apresentadas pelo jogo em relação à navegação. 
VII Congresso Brasileiro de Informática na Educação (CBIE 2018)

Anais do XXIX Simpósio Brasileiro de Informática na Educação (SBIE 2018)

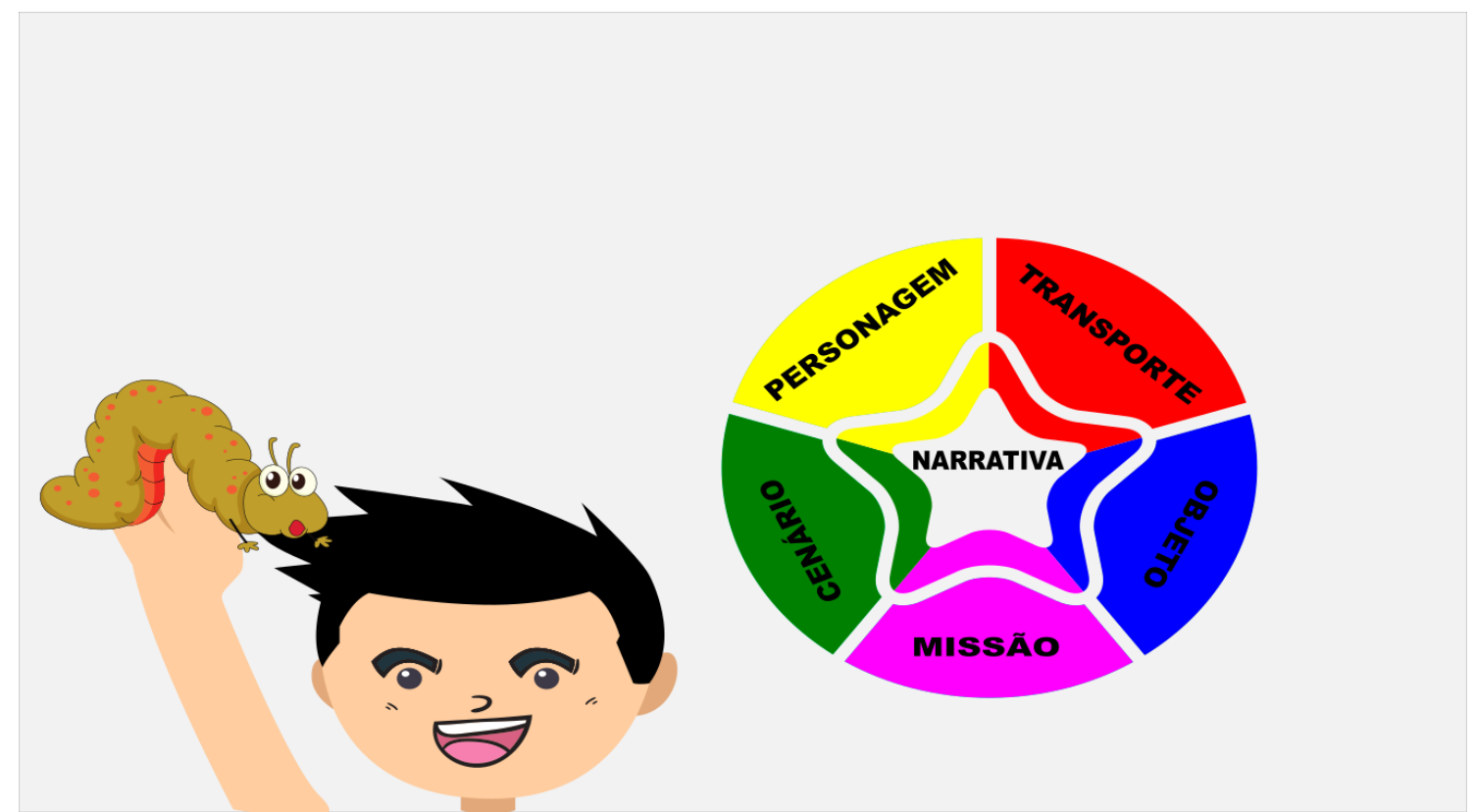

Figura 2. Possibilidades de escolha dos elementos narrativos

Com vistas a um processo de reflexão-ação-reflexão durante o desenvolvimento do game, utilizou-se também a metodologia de pesquisa-ação, onde foi possível o desenvolvimento de oficinas e atividades nos moldes analógicos com vistas à identificação de possibilidades de expansão do analógico para o digital. Sendo assim, foram realizadas atividades com objetos sólidos e jogos de tabuleiro criados exclusivamente para a amostra.

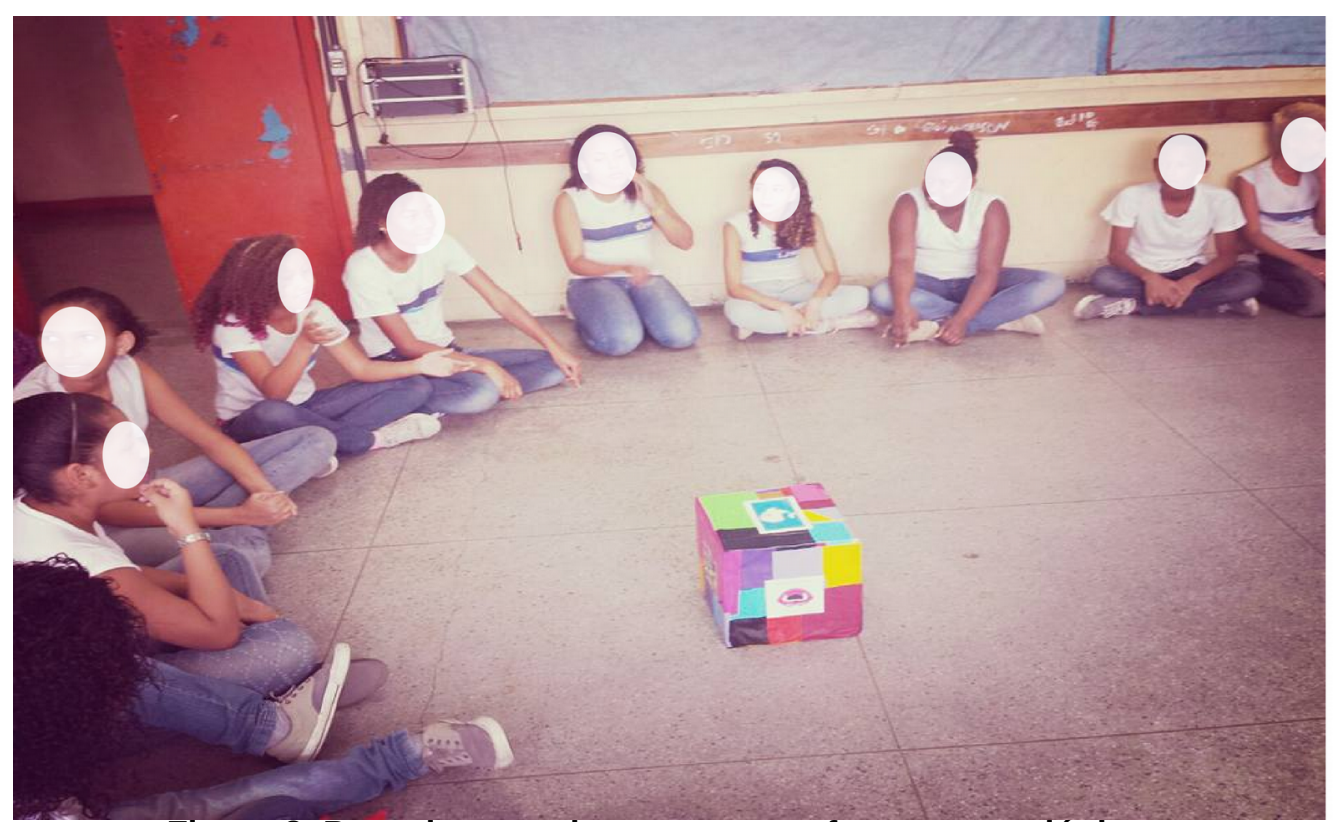

Figura 3. Prototipagem de recursos em formatos analógicos

O projeto criativo foi demasiadamente enriquecido pelos dados oriundos das atividades iniciais realizadas com a amostra, pois foi possível investigar as dificuldades que as crianças tinham em relação à criação artística e textual e estruturar uma solução tecnológica de forma que o jogo pudesse fornecer um acréscimo significativo à aprendizagem com base nos requisitos educacionais elicitados. Também utilizou-se a técnica dos Casos de Usos para identificar quais deveriam ser as funcionalidades principais e quais seriam as possibilidades de interação entre os atores e o game. 
VII Congresso Brasileiro de Informática na Educação (CBIE 2018)

Anais do XXIX Simpósio Brasileiro de Informática na Educação (SBIE 2018)

A etapa de definição de axiomas, marcadores e projeções cotadas foi essencial para a elaboração dos desafios e das possibilidades de jogada. De acordo com Pimentel[2014], no processo de construção dos axiomas, frases lógicas são correlacionadas com os textos das teorias neurocientíficas e o resultado dessa ligação é o centro de força teórica do game.

Estudos de semiótica foram necessários para auxiliar na construção dos affordances e elementos visuais, assim como o estudo das Metáforas. Segundo Lima [2008], as interfaces gráficas podem ser classificadas como um tipo de linguagem permeada por representações pictóricas com analogias e metáforas, além de uma linguagem verbal.

A utilização de analogias e metáforas de acordo com pesquisadores, é uma prática corrente no ensino das ciências por facilitar a compreensão dos conceitos científicos abstratos. A representação de um conceito ancorada em conceitos prévios já compreendidos pela criança proporciona o que Ausubel [1982] denominou aprendizagem significativa.

Sendo assim, no game proposto, buscou-se utilizar o recurso de recursividade linguística para criar uma narrativa que conta uma história sobre como se conta uma narrativa e durante este processo, o jogador produz uma nova narrativa.

Definidos os requisitos, conceitos, os axiomas, o blueprint e o mapa mental dos recursos necessários, prosseguiu-se para a arquitetura da interface do game.

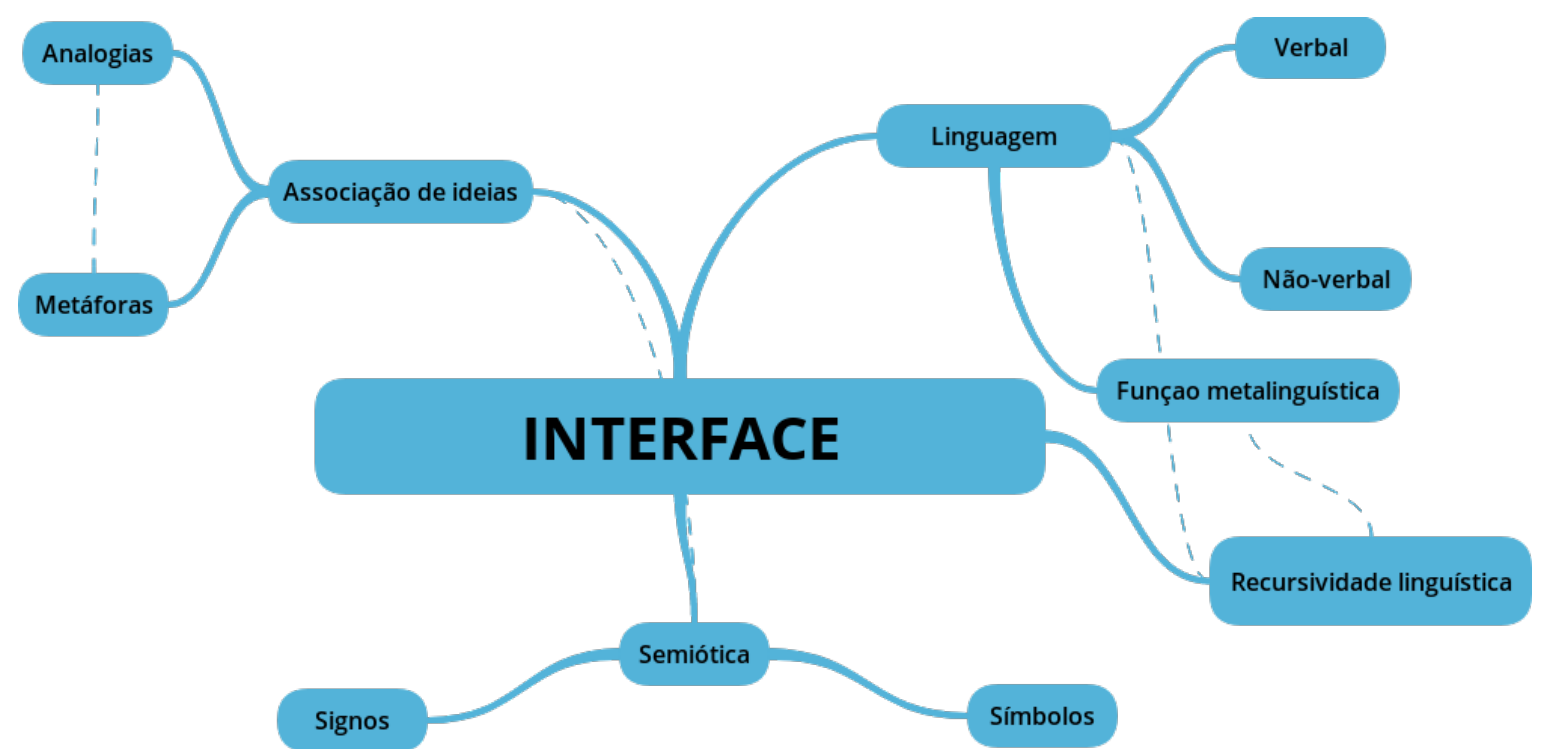

Figura 4. Mapa mental de recursos para composição de interface

\section{As metáforas do jogo}

O jogo produzido contém metáforas que representam conteúdos relacionados à criatividade, metacognição, desenvolvimento criativo, saúde e biologia, unindo ficção e verossimilhança através de elementos do quotidiano sempre imbuídos de ciências. Abaixo apresenta-se uma breve discussão e motivação das principais metáforas inseridas para compor os aprendizados esperados:

\section{1 “Coisa de outro mundo!”}

A expressão "coisa de outro mundo" surge no início da narrativa do game com o sentido habitual empregado no quotidiano ao deparar-se com um conteúdo difícil. Sabese que o ser humano tende a ignorar o que desconhece. Contudo, neste jogo, o participante é levado ao outro mundo para que o conheça e compreenda suas especificidades, vendo, desta forma, que a realização da tarefa proposta não é tao difícil quanto pode lhe parecer. A expressão "coisa de outro mundo", portanto, dá subsídio para a externalização dos acontecimentos, visto que eles acontecem em outro mundo 
VII Congresso Brasileiro de Informática na Educação (CBIE 2018)

Anais do XXIX Simpósio Brasileiro de Informática na Educação (SBIE 2018)

com o objetivo de explorar ludicamente universos que o personagem ainda não compreende.

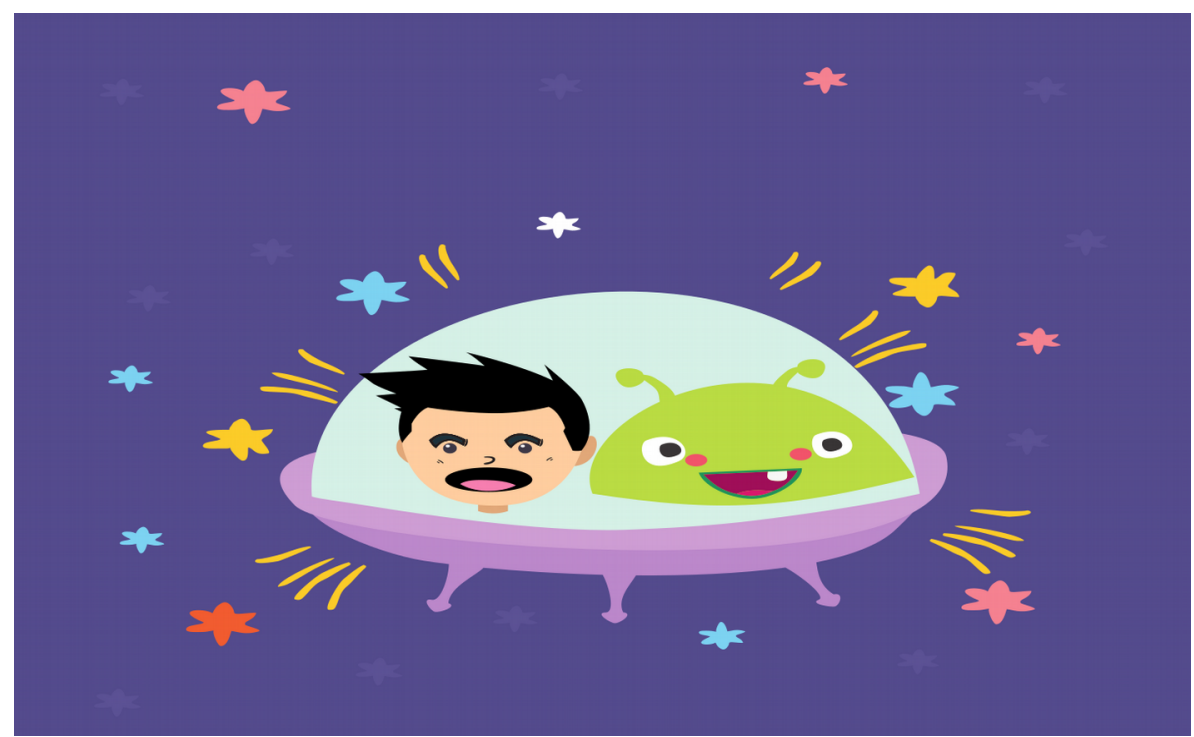

Figura 5. Representação metafórica do medo do desconhecido

\subsection{As lagartas}

Elizabeth Gilbert no livro Grande Magia - Vida criativa sem medo apresenta-nos uma elocução sobre como funcionam as ideias: “Acredito que nosso planeta é habitado não apenas por animais, plantas, bactérias e vírus, mas também por ideias. Estas são uma forma de vida energética, incorpórea. São completamente separadas de nós, mas capazes de interagir conosco - ainda que de um modo estranho. As ideias não tem um corpo material, mas tem consciência e certamente têm vontade própria. São movidas por um só impulso: o de se manifestar. E a única maneira pela qual uma ideia pode se manifestar em nosso mundo é por meio da colaboração com um parceiro humano. Ela só pode ser escoltada do nível do etéreo para o reino da realidade através dos esforços de um humano. Portanto, as ideias passam a eternidade rodopiando a nossa volta, buscando parceiros humanos disponíveis e receptivos.” [Gilbert 2015]

Este trecho do livro em especial, juntamente com todo o seu conteúdo, que incita à uma cooperação plena, humilde e alegre com a inspiração, inspirou a representação das ideias no jogo sob a forma de lagartas, insetos da ordem dos Lepidoptera que possuem estágios evolutivos até sua transformação em borboleta.

No jogo, a lagarta representa a larva de uma ideia que precisa ser cuidada até o seu estágio final. Dada a transformação, a borboleta se torna um "produto" do mundo e pode ser apreciada por muitas pessoas, assim como um texto. Desta forma, a lagarta representa a ideia de escrita de um texto e seus estágios evolutivos representam, com base na metodologia Scrum, os ciclos de construção dos elementos narrativos e 0 desenvolvimento e encadeamento de sua estrutura até o seu produto final. É preciso, pois, alimentar as lagartas para que as borboletas voem narrativas. 


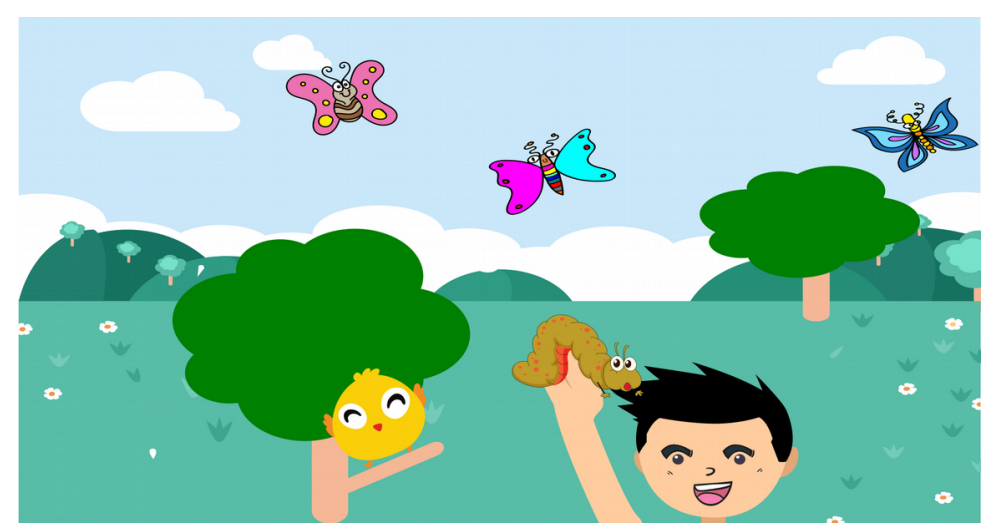

Figura 6. Representação metafórica das ideias em andamento e das ideias já processadas

\subsection{Sabedoria popular $x$ Tecnologia}

O jogo também contém uma referência à contradição entre a sabedoria popular e a tecnologia, com o objetivo de valorizar a cultura milenar e demonstrar que a Internet não contém respostas prontas para todas as questões - é necessário interpretação. Desta forma, apresenta-se uma crítica à busca por resultados prontos, pois queremos que o jogador construa ativamente tanto sua narrativa quanto seus aprendizados em relação à vida e ao universo criativo. Desta forma, pretende-se incentivar um posicionamento crítico em relação ao consumo de informação no contexto sócio-histórico atual.

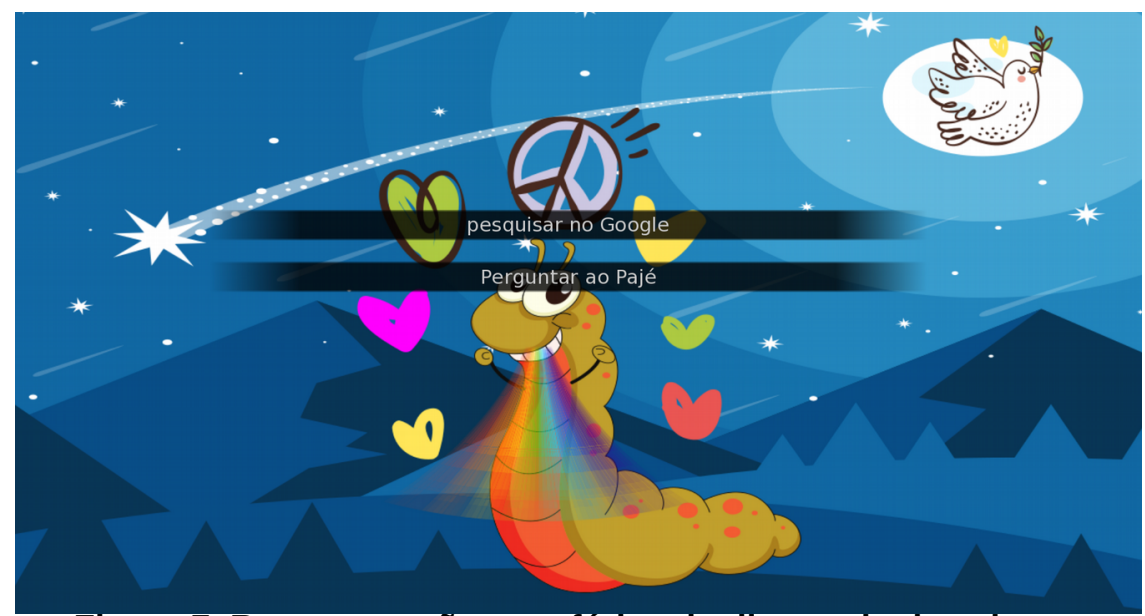

Figura 7. Representação metafórica da dicotomia de saberes

\subsection{A planta carnívora e a quebra de paradigmas}

A criatividade se revela a partir da quebra de paradigmas, a partir da quebra da linearidade e a partir das possibilidades de combinações improváveis de elementos infinitos. O game também incita a quebra de paradigmas, de modo que o jogador construa esquemas inovadores e faça seleções e combinações de forma não convencional. Para tanto, foi inserida no jogo a figura de uma planta carnívora, usualmente representada como perversa e vilã em games como Super Mario e filmes como The Day of the Triffids. Contudo, a planta carnívora no game é benevolente e necessária para a finalização da fase, isto é, enquanto o jogador năo tentar interagir com a planta carnívora, ele não conseguirá encontrar o objeto que procura, dado que Dionéia é a guardiã do objeto. O nome Dionéia é também uma referência com verossimilhança à nomenclatura binomial Dionaea muscipula de uma das espécies de plantas carnívoras. 


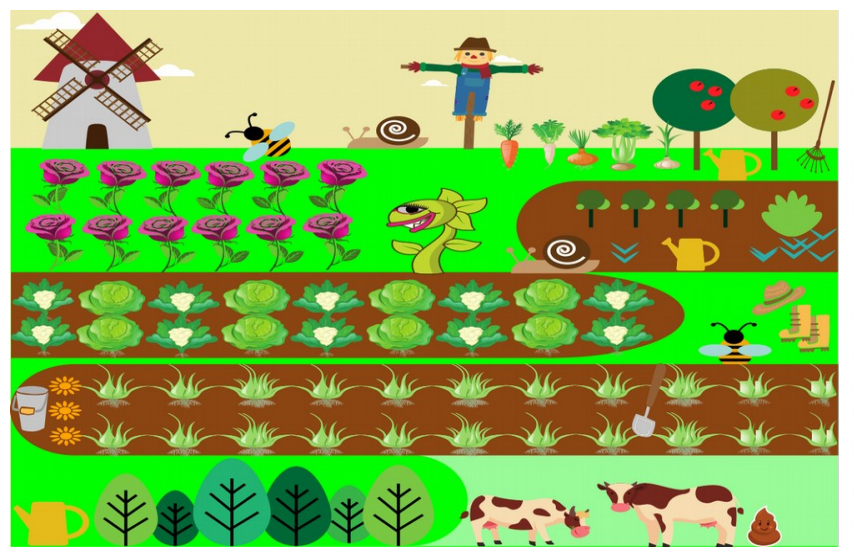

Figura 8. A planta carnívora e a quebra de paradigmas

\subsection{Referências culturais e Domínio Público}

Devido ao vasto estudo literário realizado, foi possível também a inclusão de referências a elementos nacionais, como os povos indígenas, a lenda do folclore brasileiro do Curupira e o uso de imagens de domínio público, como a imagem do Libro de los Juegos de Alfonso X, permitida pela Bridgeman Art Library v. Corel Corp.

\section{Recursos audiovisuais}

Nesta etapa buscou-se um tratamento visual do texto, bem como a criação de uma disposição harmônica dos elementos gráficos e os componentes de interação com o usuário.

A seleção das imagens foi feita de acordo com o objetivo de cada fase e cada elemento narrativo. Foram utilizados vetores e imagens dos sites https://br.freepik.com e https://www.vecteezy.com, que possibilita o uso gratuito para projetos pessoais e comerciais, e permite modificá-los para utilização em um site ou modelo de apresentação ou aplicação ou como parte de um projeto. As atribuições de autoria estão devidamente referenciadas na documentação do game.

Ressalta-se como inovação neste projeto a utilização exclusiva de Software livre. É imprescindível, no contexto sócio-histórico atual, que as quatro liberdades fundamentais - conhecer, copiar, distribuir e modificar - sejam respeitadas, possibilitando a criação, a colaboração e a independência tecnológica e cultural, onde o compartilhamento do conhecimento e a solidariedade da inteligência coletiva em nível mundial favorecem a construção de objetos educacionais de qualidade. Os softwares utilizados nesta etapa foram Inkscape, Gimp, Kolourpaint, writer, pluma, Jedit, além de Ren’py e a linguagem de programação Python.

\section{Considerações finais e aplicações futuras}

Este artigo demonstrou a representação de conceitos educacionais interdisciplinares na fase de projeto criativo, etapa que integra um dos quatro grandes processos definidos por Motta[2014] na metodologia de desenvolvimento de um game inteligente. Finalizada esta etapa, o projeto encontra-se atualmente na fase de projeto interacional, onde busca-se encadear os produtos dos processos anteriores para determinação de eventos e de crivos que auxiliarão a construção do engenho capaz de integrá-los, mapear os dados cognitivos durante as jogadas e apresentar os relatórios para análise, facilitando o processo de avaliação do desenvolvimento criativo da criança.

Como resultados desse processo, além do produto tecnológico, isto é, a interface do game inteligente, tem-se também um produto literário, isto é, a narrativa construída para compor o enredo do game. Há a intenção de publicação futura desta narrativa em meio físico ou Ebook como forma de contribuir ainda mais para a Educação brasileira.

Destaca-se também como contribuição o estabelecimento do template de um personagem explorar um conteúdo "de outro mundo". Esse template abre margem para que futuramente diversos conteúdos de diversas disciplinas possam ser explorados neste game, em adaptações dele ou em outros suportes midiáticos. Sendo assim, qualquer 
VII Congresso Brasileiro de Informática na Educação (CBIE 2018)

Anais do XXIX Simpósio Brasileiro de Informática na Educação (SBIE 2018)

conteúdo que pareça difícil a uma amostra de crianças pode ser inserido nesta abordagem.

Também destaca-se como positiva a criação de um produto feito exclusivamente com software livre, obras de domínio público, conteúdos audiovisuais gratuitos e licenciados, com interdisciplinaridade e referências à cultura e ao folclore nacional.

Como possibilidades futuras para o trabalho desenvolvido nesta etapa, pretendese ampliar os estudos para verificar a viabilidade de aferição de heurísticas de interface e adequação às recomendações do World Content Accessibility Guide do World Wide Web Consortium.

O projeto criativo é concebido como parte fundamental no processo de desenvolvimento de um game inteligente, e fica clara a importância do estudo dos signos e metáforas para a concretude do projeto, à medida que metáforas formam modelos cognitivos com estruturas da organização do conhecimento e é aberta para inúmeros novos caminhos de pensamento. Baseando-se na proposição de que "um objeto de conhecimento reúne em uníssono todo o conhecimento do universo" e, portanto, "cada objeto como holograma do universo tem em si a competência de todos os conhecimentos possíveis" Marques [2017], fica evidente a importância das metáforas não apenas como forma de representação de conhecimentos e sentidos no jogo, mas também como agentes de transitividade entre os conhecimentos e a interdisciplinaridade. A compreensão das representações e a forma de transitar entre os conhecimentos constitui uma forma de acesso à estrutura cognitiva dos indivíduos. Nesta pesquisa, portanto, a interdisciplinaridade foi possibilitada por um amplo trabalho de criação de metáforas e signos que foram representados virtualmente através da tecnologia do game inteligente, o qual foi concebido com base nas dificuldades identificadas na amostra.

Este artigo descreveu a conclusão de mais uma etapa integrante de um grande projeto e espera-se que a integração entre as partes seja capaz de proporcionar um grande avanço em termos de mapeamento cognitivo e fornecimento de estímulos a saltos cognitivos em relação às competências do domínio abordado.

\section{Referências}

Ausubel, D. (1982) Aprendizagem significativa: a teoria de David Ausubel. São Paulo, Moraes.

Bandura, A. (1977). Social Learning Theory. Englewood Cliffs, N.J: Prentice-Hall.

Barthes, R. (2002) A aventura semiológica. S.Paulo. Martins Fontes.

FREEPIK. Vetores grátis. Disponíveis em <https://br.freepik.com/vetores-gratis/>

Gilbert, E. (2015) Grande Magia - vida criativa sem medo. I ed. - Rio de Janeiro. Editora Objetiva

Lima, N. (2008) Metáforas e interfaces gráficas: Contribuições para uma aprendizagem significativa da Informática. Dissertação de Mestrado. Centro Federal de Educação Tecnológica de Minas Gerais. Belo Horizonte.

Machado, Raquel et al (2016) "Ler, escrever e programar: atividades essenciais para o desenvolvimento cognitivo na era da informação" Sánchez, J. (2016) Editor. Nuevas Ideas en Informática Educativa, Volumen 12, p. 511 - 516. Santiago de Chile.

Marques, C. V. M. (2017) "Eica - Estruturas Internas Cognitivas Aprendentes: Um Modelo Neuro-Computacional Aplicado À Instância Psíquica Do Sistema Pessoa Em Espaços Dimensionais”. Universidade Federal do Rio de Janeiro.

Motta, C. L. R. et al. (2012) “Jogo da Trilha Topológica: Um Game Inteligente em Ação”, Anais do XXIII Simpósio Brasileiro de Informática na Educação - SBIE

Motta, C. L. R., Oliveira, C., et al. (2014) "Templates cérebro-mente - um modelo diagramático aplicado a jogos inteligentes ".

Motta, C. L. R. et al. (2014) Sistemas educacionais inteligentes in Grandes desafios da computação no Brasil - Relatos do $3^{\circ}$ Seminário. SBC.

Murray, Janet H. (2003) "Hamlet no Holodeck: o futuro da narrativa no ciberespaço." 
VII Congresso Brasileiro de Informática na Educação (CBIE 2018)

Anais do XXIX Simpósio Brasileiro de Informática na Educação (SBIE 2018)

Itau Cultural, Editora Unesp, São Paulo.

Pimentel, Ana. P. C. (2014) Uma proposta de identificação de assinaturas cognitivas com padrões de pensamento criador. Dissertação de mestrado. Universidade Federal do Rio de Janeiro

Pimentel, Ana P. C. (2014) Fases de Construção de um Jogo Virtual para Mensurar a Inovação e a Heurística. Nuevas Ideas en Informatica Educativa TISE 2014

Seminério F. et al.(1987). Elaboração Dirigida : um caminho para desenvolvimento metaprocessual da cognição humana. Rio de Janeiro: Instituto Superior de Estudos e Pesquisas Psicossociais. Cadernos do ISOP, nº 10, Rio de Janeiro, Ed. FGV.

VECTEEZY. Vector Graphics. Disponíveis em <https://www.vecteezy.com/>

Vygotsky, L. (2001)Pensamento e Linguagem (1896 - 1934) Edição Eletrônica. Jahr. Ebooks Brasil.

Xavier, Guilherme (2010) “A condição eletrolúdica: cutura visual nos jogos eletrônicos”, Editora Novas Ideias, RJ. 